\title{
Expressing Procedural Relationships in Multilingual Instructions*
}

\author{
Judy Delin \\ Department of English Studies \\ University of Stirling \\ Stirling FIS9 4LA, UK \\ email: J.L.Delin@̂stirling.ac.uk
}

\author{
Anthony Hartley Cécile Paris Donia Scott Keith Vander Linden ${ }^{\dagger}$ \\ Information Technology Research Institute \\ Zniversity of Brighton \\ Lewes Road \\ Brighton $\mathrm{BN}^{2} 24 \mathrm{AT}, \mathrm{LK}$ \\ email: $\{$ Tony.Hartley, Cecile.Paris,Donia.Scott,Keith.Vander-Linden\}@itri.bton.ac.uk
}

\begin{abstract}
In this paper we discuss a study of the expression of procedural relations in multilingual user instructions, in particular the relations of Generation and Enablement. These procedural relations are defined in terms of a plan representation model, and applied in a corpus study of English, French, and Portuguese instructions. The results of our analysis indicate specific guidelines for the tactical realisation of expressions of these relations in multilingual instructional text.
\end{abstract}

\section{Introduction}

In user instructions, it is common to find expressions like:

(1) Pull down and remove the white plastic tray that holds the video cable and unpack the calble. (Apple)

Here we have what appears to be a simple expression of seruential actions. The reader is expected to pull down the white plastic tray, remove that tray, and then unpack the cable. Current studies of instructional text (e.g.: Rösner and Stede, 1992; Vander Linden, 1993) typically represent the relationship found here in a simple. multi-dependent structure such as that provided by the Sequence schema in Mann and Thompson's Rhetorical Structure Theory (RST) (1988) (see figure 1A). This rhetorical structure, which represents three sequential actions, directly matches the grammatical forms used in the actual text. Indeed, this secuential execution is precisely what the instruction writer desires the reader to

*This work is supported by the Commission of the Enropean Uniou Grant LRE-62009, the Eugineering aud Physical Scieuces Research Council Grant J19221, aud the BC/DAAD ARC Project 293.

${ }^{\dagger}$ Authors are presented iu alphabetical order. do in this context. The complication comes when one finds, sometimes even in the same instruction manual, an alternate form of expression for the very same user action, such as the one shown in the following:

(2) Pull down and remove to unpack the video cable. (Apple)

RST analysts would most likely represent this with a purpose relation, as in figure 1B. Clearly, the representation formalism fails to capture the common semantics of these two examples.

This problem may be only rarely encountered in a monolingual context, but is exceedingly common in a multilingual environment (Delin et al., 1993). Consider the following example, taken from a trilingual, translated instruction manual for a step-aerobics machine:

(3) The stepping load can be altered by loosening the locking lever and changing the position of the cylinder foot.(Liftmaster)

(4) Pour modifier la charge d'appui. desserrer To modify the load stepping loosen les leviers puis déplacer le pied des the levers then change the foot of the vérins.(Liftmaster) cylin.der foot

(j) Nach Lockern der Klemmhebel kann After loosening of the levers can durch Verschieben des Zylinderfußes die by pushing of the cylinder foot the Tretbelastung verändert werden.(Lift.master) load changed be.

Here we find the same information being conveyed through expressions that exhibit rather clifferent RST 


\section{A. Example 1}

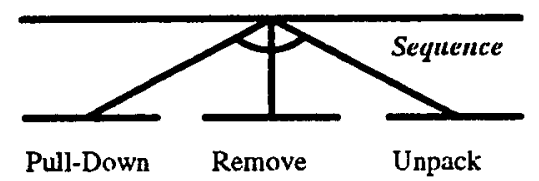

\section{B. Example 2}

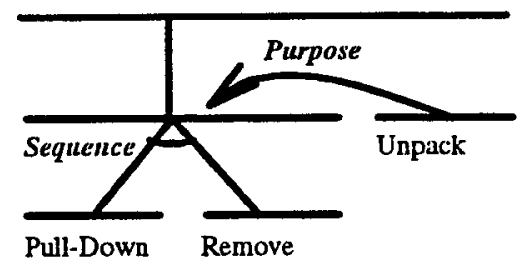

Figure 1: Contrasting Discourse Structures Representations

structures (see Figure 2). The English version is perhaps best characterised as a Means relation, whereas the French is a Purpose relation and the German a Circumstance.

The problem examples such as these raise for generation is twofold: (a) how do we endlow our systems with the necessary flexibility to generate alternative expressions of the same basic information and (b) given this flexibility: how do we determine which of the available expressions are appropriate? The root of these problems is that, to date, research in the generation of instructions has failed to take account of the precise procedural relations that underlie the texts. In this paper, we make an excursion into the philosophical literature on Action Theory and the AI literature on plan recognition to find solidly defined procedural relations which can capture the underlying semantics of actions and their relationships in a way that will prove useful for our generation task: building multilingual instructional text generation systems. We present the results of part of an ongoing investigation of the utility of the Generation and Enablement relations in contributing to onr stated goal.

\section{Procedural Relations}

The philosopher Alvin Goldman identified two basic procedural relations, Generation and Enablement, that apply between actions in a task (Goldman, 1970). These have been formalised within the Planning community and shown to be useful constructs for plan recognition (Pollack, 1986; Balkanski, 1993). In this section we review the definitions of Generation and Enablement and describe how we have applied them in our analysis of a corpus of instructional texts in English. French and Portuguese.

\section{The Generation Relation}

A simple test of Generation. holding between action pairs is whether it can be said that by performing one of the actions $(\alpha)$, the other $(\beta)$ will automatically occur (Pollack, 1986); if this is the case then it can be said that $(\alpha)$ generates ( $\beta$ ). According to Goldman, Generation is a relation applying between two act-tokens in certain well-defined situations. For purposes of producing instructions, however, we find it necessary to view Generation as holding between act-types, since we are dealing with actions that have not yet taken place; we are able to do this without distorting the general theory that Goldman presents (cf. Pollack, 1986). Here are some canonical examples of this relation taken from Goldman:

(6)(a) John flips the switch. $(\alpha)$

(b) John turns on the light. ( $\beta$ )

where flipping the switch generates turning on the light and

(7)(a) John moves his queen to king-knight-seven. $(\alpha)$

(b) John checkmates his opponent. (B)

where moving the queen to king-knight-seven generates checkmating the opponent.

Following Goldman, Generation holds in cases where:

- the actions concerned are performed by the same agent (e.g.; John). For reasons that will become clearer later on, we have found it necessary to qualify and extend this part of the definition to actions performed or perceived to be performed by the same human agent.

- the relation is asymmetric: if the agent does $\beta$ by doing $\alpha$ then he does not do $\alpha$ by doing $\beta$ (e.g.: the switch cannot be flipped by turning on the light).

- neither action is subsecquent to the other (e.g., the light does not come on after the switch is flipped, or vice versa $)^{\perp}$. A useful linguistic test for this is the invalidity of the expression " $\alpha$ and then $\beta$ ".

- the actions are not co-temporal. Simply stated, if $\alpha$ and $\beta$ are co-temporal, then one could validly say " $\alpha$ while also $\beta$ " and vice versa, for example, "John strummed the guitar while also wriggling his toes". These actions are co-temporal, but not related by Generation. One could not validly say that John flipped on the switch while also turning on the light, or moved his queen to king-knight-seven while also checkmating his opponent.

- if the agent had not done $\alpha$, then he would not have done $\beta$;

- there is a (set of) condition(s) $\gamma$ (say; George making sure that the light bulb was screweed in) such that

\footnotetext{
${ }^{1}$ Accorcling to Goldman, this holds even if the light does not come on for a few secouds after the switch was Hipped.
} 
A. Example 3 (English)

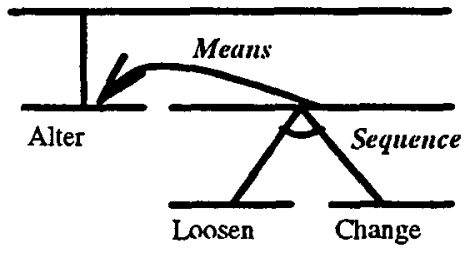

B. Example 4 (French)

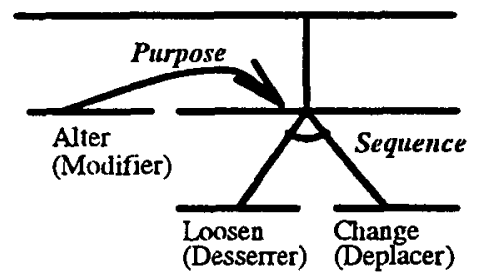

C. Example 5 (German)

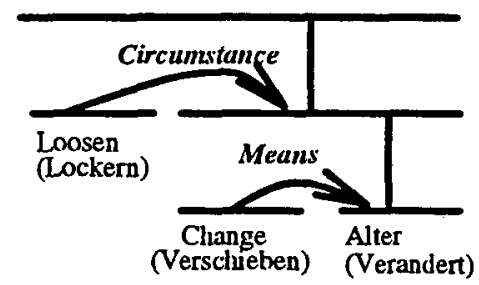

Figure 2: Contrasting Multilingual Discourse Structures Representations

- the conjunction of $\alpha$ and $\gamma$ entails $\beta$;

- if $\gamma$ had not obtained, the performance of $\alpha$ would not have led to $\beta$.

A Generation relation between action pairs can receive a variety of linguistic realisations. Consider the following semantically equivalent instructions:

(8) Checkmate your opponent by moving your queen to king-knight seven.

(9) Move your queen to hing-knight seven to checkmate your opponent.

(10) If you want to checkmate your opponent, move your queen to hing-knight seven.

Two points are worthy of note here. The first is that although cansation plays a key role in Generation, $\beta$ is not in a strict sense caused by $\alpha$; rather, $\beta$ is the action of (to use Goldman's term) 'bringing about' the state that is the direct result of performing $\alpha$ under specific conditions $(\gamma)$. Referring back to example 6 , John's flipping of the switch causes the event of the light coming on; John's 'bringing about' of this event can be captured by the expression 'turning on the light'.

The second point to be noted is that in the domain of instructions for mechanical and electronic objects there is also a hidden agent the machine itself: as an agent acting on behalf of the user. This leads to the possibility of equivalence of expressions such as "I deleted the file" and "My computer deleted the file". We consider these to be equally valid expressions of the generated part of a Generation relation. For example, we also count instructions such as the following (for using a cooking utensil)

(11) Imprimez un monvement de rotation à Impart a movement of rotation to

la garniture, elle se démonte.(Darty)

the plate it itself removes.

as instances of Generation. Expressions of generated actions with non-human agents are relatively uncommon in English instructions but (as will be discnssed later) this is not true of all langruages.

\section{The Enablement Relation}

Instructions alwo include expressions such as the following:
(12) You must restart your Macintosh to use your new software.(Microsoft)

(13) Before using your data cartridge, allow it to acclimate to your operating environment for eight hours or for the amount of time it has been exposed to dissimilar conditions whichever is less.(3M)

(14) 2 Double-click the Installer icon with the mouse button.

The installer displays an introductory screen.

3 Click the OK button.(Microsoft)

(15) In order to operate remote control, you must first have noted or memorised your code.(Bell)

These are clearly not instances of Generation, since the execution of any nember of the action pair does not 'automatically' result in the execution of the other. In each case, some intermediating action(s) is required. Following Goldman (1970), this type of relation between action pairs is most commonly referred to as Enablement (Pollack: 1986; Balkanski, 1993; Di Eugenio, 1992). Goldman does not provide a formal definition of this relation, but Pollack gives a useful general definition: " $\ldots$ when $\alpha$ enables $\beta$, then the agent needs to do something more than $\alpha$ to guarantee that $\beta$ will be done." (Pollack, 1986, page 40). A more detailed definition is provided by Balkanski: " ...Action $A_{1}$ enables action $A_{3}$ if and only if there is a set of conditions, $C$, such that one of the conditions in C, $C_{i}$, holds as a result of the performance of $A_{1}$, and either there is a third action $A_{2}$ such that $A_{2}$ conditionally generates $A_{3}$ under $\mathrm{C}$, or $\mathrm{C}$ is the executability condition of $A_{3} . "$ (Balkanski, 1993, page 41).

Enablement applies to all four examples above because in them, one action brings about conditions that are necessary; but not necessarily sufficient for the subsequent performance of the other. In example 12, the reader must restart the Macintosh in order to be in a position to be able to use the new software. There are in fact other actions necessary for the use of the software, but they are not mentioned. Acclinating the cartridge in example 13 is not sufficient to make it in use. Similarly. in example 14, clicking on the Installer icon only brings about a set of conditions (in this case, the appropriate menu) for the user to click the OK button. In example 
15. the reader must know the code in order to be able to operate the remote control, although knowing the code is not enough.

Note that in some cases of Enablement (e.g., in 12 and 13), the intermediate action can in fact be performed in the absence of the enabling condition; the result will simply be that the enabled action will not occur. In others however (e.g.: examples 14 and 15), the intermediate action is impossible to perform when the enabling condition does not hold.

An important property of Enallement which distinguishes it from Generation is that the enabled and enabling actions can be carried out by different human agents. Goldman alludes to this in his discussion of example 6, where he introduces a necessary condition for the Generation of John turning on the light: George's screwing the bulb into the socket.

As in the case of some of the Generation examples we saw before, actions in Enablement relations can be expressed as an activity carried ont by a human agent or by, say, a machine or in terms of the associated state of the agent. For example, example 10 could expally have been expressed as the following:

(16) In order to operate remote control, you must know your code.

(17) For the remote control to operate, you must first have noted or memorised your code.

\section{A Formalisation}

From our discussion so far, it is clear that the relations of Generation and Enallement shonld be identifiable aspects of plans for performing procedures. We employ a plan formalism that is a simple extension of STRIPS-styled operators developed by Fikes (1971) and expanded in the NOAH system (Sacerdoti, 1977). In our representation, plans comprise:

goal(s): an action (or set of actions) which motivate(s) the use of the plan;

constraints: states which must hold before a plan can be employed. Constraints cannot be achieved through planning;

side-effects: states which arise as unplanned effects of carrying out a plan;

a body: an action or action complex which executes the plan; if these are not primitive, they can themselves be achieved through another plan;

preconditions: an action or action complex which, when carried out, leads to conditions necessary for the successful execution of the plan; i.e, the body will be executable but its execution will not generate the goal (even if the constraints hold) unless the precondition is realisable. Preconditions can be planned for. ${ }^{2}$

\footnotetext{
'This type of preconditious relates to Pollack's (1986) generation-enabling condition.
}

Plans must minimally have a body and goal. Actions, in turn, comprise:

constraints: these have the same properties as the constraints on plans;

side-effects: these also have the same properties as the side-effects on plans;

effects: states which arise from the bringing-about of the action;

preconditions: like the preconditions of plans, these are either an action or an action complex and can be planned for. Unlike the preconditions of plans, however, their effects must hold before the action can take place (i.e., the action cannot result if the precondition does not hold). ${ }^{3}$

Actions must minimally have an effect. Finally, states can have evidences. These are phenomena which signify that the state holds.

As in all STRIPS-based planning formalisms, plans in our representation can have associated sub-plans. In our case, sub-plans arise through the body of a plan, the preconditions of a plan, or through the preconditions of an action.

Having set out this scheme, we can now proceed to identify instances of Generation and Enablement within our representation for instructions:

$\alpha$ generates $\beta$ iff $\alpha$ is the body of a plan $\epsilon$ whose goal is $\beta$.

$\alpha$ enables $\beta$ if $\alpha$ is a precondition of a plan $\epsilon$ and $\beta$ is the goal of plan $\epsilon$, or if $\beta$ is the body of $\epsilon$ and $\alpha$ is a precondition of $\beta$.

Figure 3 shows graphically the relationship between the notion of a plan and the Gerteration and Enallement relations.

\section{Generation and Enablement in Instructions}

We have shown through examples that Generation and Enallement can be expressed in a variety of ways. In instruction generation, it is clearly important to signal the correct relationship between actions, since failure to do so could lead to situations where the user diligently carries ont the action without achieving the desired effect. For example, if the following Enablement relation

(18) To clean the case: disconnect the power plug.(Microsoft)

is misperceived as Generation (as it might be were it to be expressed as "Clean the case by disconnecting the power plug"), the user would believe that by disconnecting the plug she would be guaranteed to achieve her goal of cleaning the case; this would only result in frustration, bewilderment and a still dirty case. We are thus

\footnotetext{
${ }^{3}$ This notion is closely related to Balkanski's (1993) definition of executability condition.
} 


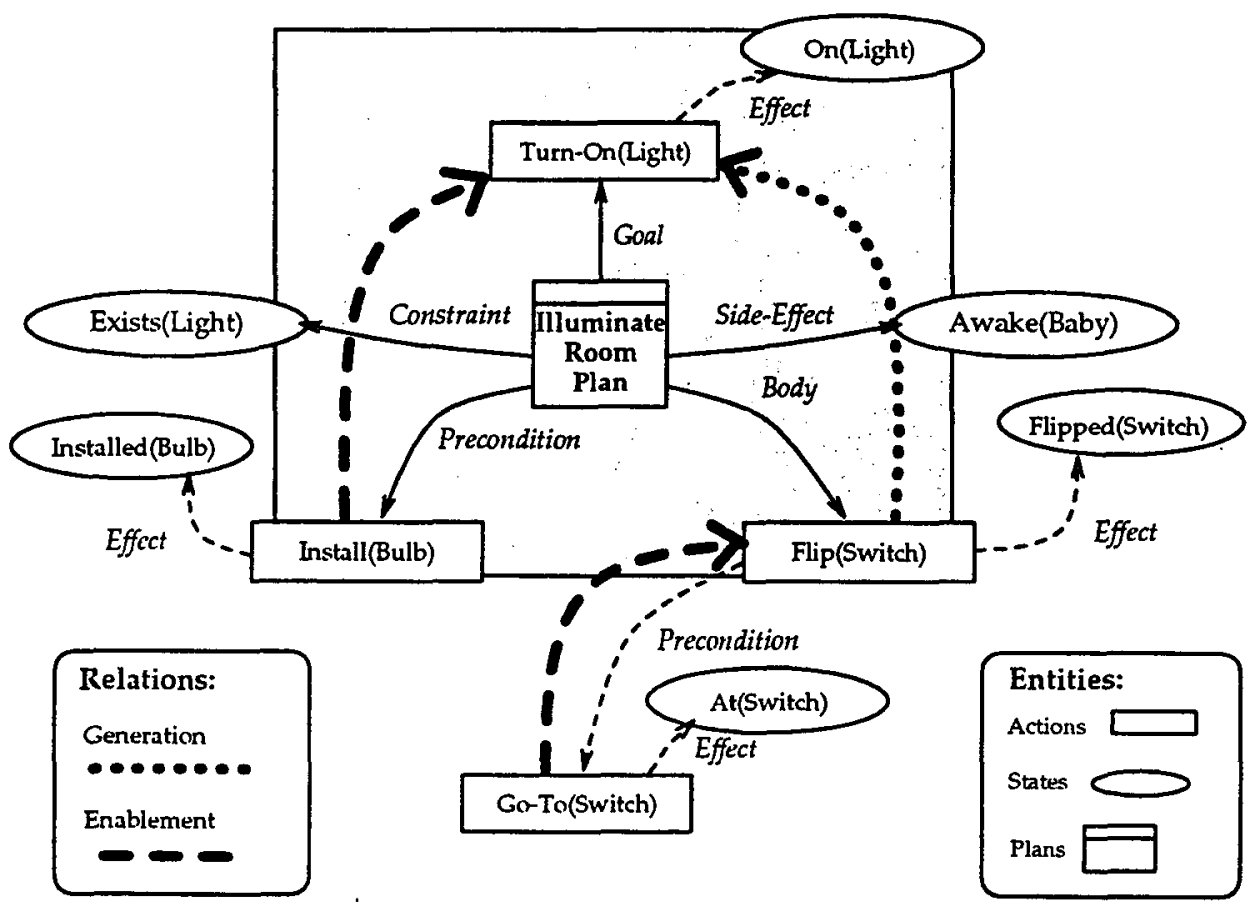

Figure 3: Generation and Enablement in the Plan for Turning on the Light

concerned to generate only the appropriate expressions for Generation and Enablement.

Our approach to this problem is to look to the data: we are analysing a corpus of commercially-produced instructions for manual tasks to extract the mappings between Generation and Enablement and linguistic form. The results of our study inform our design of a system for generating draft instructions in multiple languages from a common, language-independent, representation. We describe some of our results in this section, based on our analyses of English. French and Portuguese instructions.

The data we report are from original texts written in the particnlar language being ardresser; they are not the product of translation. Our method of analysis is to idlentify instances of Generation and Enablement from the corpus and to register its grammatical form. We report here only on data for which we all agree on the chosen procedural relationship.

In analysing the data, our main concern has been to determine:

1. What are the commonly used mappings from Generation and Enablement onto language?

2. Which forms are ambiguous between Generation and Enablement and how can we exploit this information for generation?

3. What are the factors that influence the 'appropriateness: of a selected form?

\section{The English Results}

The English corpus is made up of 451 clanses (approximately 3500 words) taken from 9 instruction manuals intended for non-expert readers. A detailed accounting of the grammatical forms used to express Generation relations is shown in table 1. Similar statistics for $E n$ ablement relations are shown in table 2 .

The general results of these mappings are shown graphically in figure 4, and as can be seen, there are grammatical forms which tend to be exclusively used for either Generation or Enallement (imperative + by, sequence, and before conditions) and other forms that are common to both relations (to infinitives and for phrases).

The most common forms shown in tables 1 and 2 appear to be clear patterns of use which can be exploited in text generation, rather than just random selections or artifacts of this particular corpus.

Expressing Generation in English In our corpus, Generation relations tend to be expressed with either the imperative + by, the imperative + to infinitive, or one of a set of for phrases. These forms, which together constitute $80 \%$ of the Generation relations identified, are exemplified here in examples from manuals for a Macintosh colour monitor and for a Bell telephone answering machine:

(19) If your computer system does cause interference to radio or television reception, try to correct the interference by using one or more of the following mea- 


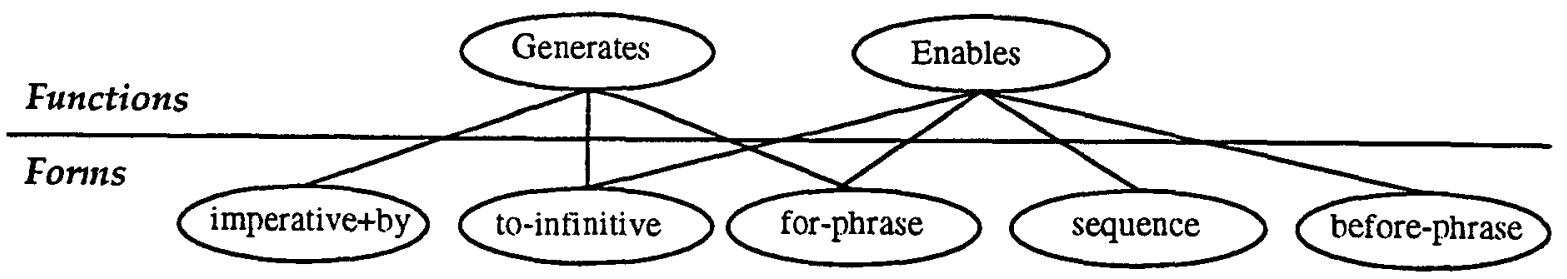

Figure 4: The English function to form mapping of Generation and Enablement Relations

\begin{tabular}{lcc} 
Grammatical Form & Count & Percentage \\
\hline To Infinitive & 30 & $46.1 \%$ \\
For Phrases & 14 & $21.5 \%$ \\
Imperative + by & 8 & $12.3 \%$ \\
Clause Sequences & 3 & $4.6 \%$ \\
7 other forms & 10 & $10.4 \%$ \\
\hline \multicolumn{1}{c}{ Total: } & 65 &
\end{tabular}

Table 1: The frequency of English grammatical forms for Generation Relations

\begin{tabular}{lcc} 
Grammatical Form & Count & Percentage \\
\hline Sentence Sequence & 22 & $47.8 \%$ \\
To Infinitive & 10 & $21.7 \%$ \\
For Phrases & 5 & $10.9 \%$ \\
Before Condlitions & 4 & $8.7 \%$ \\
Imperative + by & 1 & $2.2 \%$ \\
4 other forms & 4 & $8.7 \%$ \\
\hline \multicolumn{1}{c}{ Total: } & 46 &
\end{tabular}

Table 2: The frequency of English grammatical forms for Enablement Relations

sures:(Apple)

(20) To interrupt playback; rotate the VOLUME knob towards the rear, past the "click'.(Bell)

(21) See your anthorized Apple dealer for information on screen save programs. (Apple)

In example 19, the action of using "one or more of the following measures" generates the action of correcting the interference. They are performed by the same hinman agent, asymmetric, one does not occur before the other, and there exist the specified conditions $\gamma$; the same pattern is repeated in examples 20 and 21 .

The first question is what to make of the gaps? Why are Generation relationships so infrernently expressed nsing sequences of clauses, and never expressed using before clauses? This clearly follows from the definition of Generation that neither action can be subsequent to the other, a relationship that is strongly implied by sequences. There are cases where sentence sequences are used to express Generation, but these are infreciuent and occur in very specific syntactic situations (Vander Linden, 1993). In general, grammatical forms which typically function as expressions of sequence should be avoided when expressing Generation relationships because they tend to mislead the reader by suggesting the performance of two distinct actions.

Concerning the question of identifying the contexts in which the imperative + by, the to infinitive, and the for phrase arise, it has been observed that syntactic constraints and lexical availability appear to motivate the use of the imperative + by form and the for phrasal forms (Vander Linden, 1993).

Expressing Enablement in English Enablement relations tend, in $89 \%$ of the cases, toward before conditions, one of a set of sequence forms, imperative + to infinitive and other for phrasal types. Examples of these forms are given here:

(22) Quit all applications before beginning the following procedure.(Microsoft)

(23) Switch off at the mains, disconnect the power adaptor and remove the casset te. Wipe the tape heads and pinch roller gently with a cotton-wool bud dipped in tape head cleaning fluid or methylated spirits.(Bell)

(24) Return to seat to place calls.(Airfoue)

(25) PLEASE SAVE THESE INSTRUCTIONS FOR FUTURE USE.(Playsclıool)

In example 22, quitting all applications is an action intended to bring about a set of conditions compatible with "beginning the following procedure", as are the actions of removing the cassette, returning to the seat, and saving these instructions in examples 23,24 , and 25 respectively. None of them are sufficient to achieve their intended goal.

The gap in the expressions of Enablement is that they are seldom expressed using the imperative + by form. As can be seen in tables 1 and 2, there is only one $E n$ ablement expressed as an imperative + by as opposed to eight Generation relations expressed that way. It seems inappropriate, for instance, to express the actions in example 24 as "Place calls by returning to your seat" because it tends to imply that returning to your seat is all you have to do to achieve the goal. We, thus, would restrict the use of the imperative + by to the expression of Generation relations only.

\section{The French Results}

The French corpus comprises 14 sets of instructions 


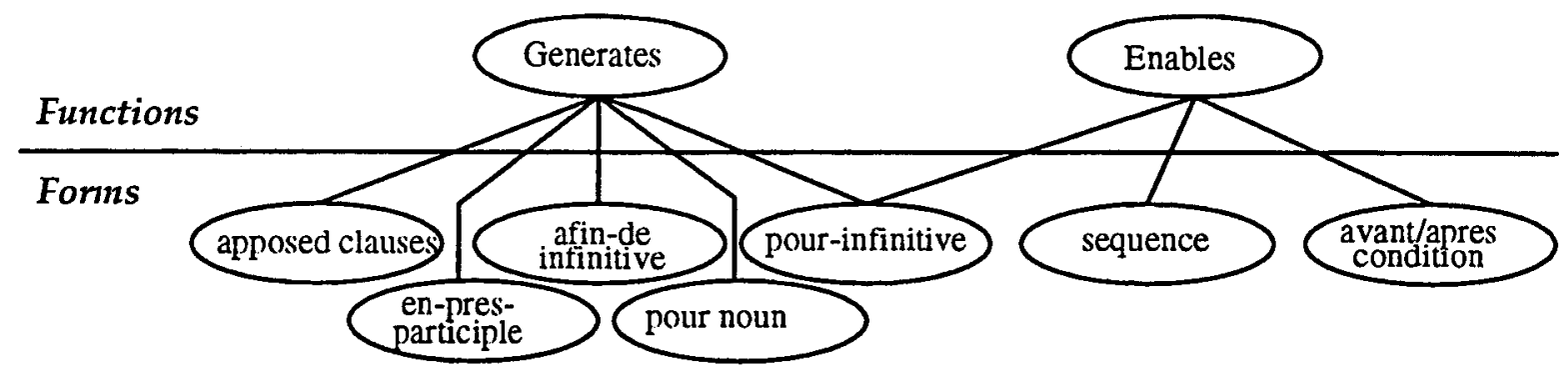

Figure $\overline{3}$ : The French function to form mapping of Generation and Enablement Relations

\begin{tabular}{lcc} 
Grammatical Form & Count & Percentage \\
\hline En-present-participle & 12 & $33.3 \%$ \\
Pour-infinitive & 8 & $22.2 \%$ \\
Apposed clause & 5 & $13.9 \%$ \\
Pour-noun & 4 & $11.1 \%$ \\
Afin-de-infinitive & 4 & $11.1 \%$ \\
3other forms & 3 & $8.3 \%$ \\
\hline \multicolumn{1}{c}{ Total: } & 36 &
\end{tabular}

Table 3: The frequency of French grammatical forms for Generation Relations

\begin{tabular}{lcc} 
Grammatical Form & Count & Percentage \\
\hline Et-sequence & 13 & $40.6 \%$ \\
Pour-Infinitive & 6 & $18.8 \%$ \\
Avant-conditions & 6 & $18.8 \%$ \\
Après-conditions & 4 & $12.5 \%$ \\
2 other forms & 3 & $9.4 \%$ \\
\hline \multicolumn{1}{c}{ Total: } & 32 &
\end{tabular}

Table 4: The frequency of French grammatical forms for Enablement Relations

for French-produced domestic appliances and for home improvement. Thus, the texts are intended for nonspecialists. Most have a word-connt of between 200 and 400 words. We set a target of collecting some 30 examples of each relation, expressed in single sentences rather than across sentence boundaries. The examples were vetted by a native speaker.

The statistical analysis of surface forms is given in tables 3 and 4 . The graphical representation of these data, shown in figure $\overline{5}$, indicates only one forn to be common to both relations.

Expressing Generation in French French has a realisation of this relation that is distinct from English, as we showed in example 11, and can see again here in an instruction from a Philips telephone manual:

(26) Appuyer 2 fois sur la touche MEMO. Press 2 times on the key MEMO;

le numéro se compose alors

the number itself dials then
automatiquement.(Philips) automatically.

Here the information is expressed through clauses which are in apposition. The same information could have been expressed as:

(27) Appuyer $\ldots$ sur la touche pour Press ... on the key for composer ... to dial $\quad .$.

It is examples such as these that led us to modify Goldman's definition of Generation. In French it is common to achieve agent deletion by using a reflexive verb whose syntactic subject is the semantic theme of the corresponding full transitive verb. Although there is no explicit agent of the action, agency is readily inferred and the spirit of Goldman's definition is preserved. Moreover, the word "automatically" is in a sense redundant. serving to emphasize the fact that the result is achieved with no further action on the part of the agent.

Agent deletion may also be achieved by de-verbal nominalization, as in the following examples from manuals for a cooking utensil and for do-it-yourself home improvement:

(28) La poussée du ressort interne dégage The push of the spring internal releases

le poussoir.(Darty)

the push button.

The most frequent realization is by the en present participle form, for example in:

(29) Soulever mannellement le flottenr au Raise manually the float to the maximum en tirant sur le maximum by pulling on the

bras.(Castorama 50.11)

arm.

Although it is tempting to view this form as the direct equivalent of "by + ing", it is also available for relating distinct co-temporal actions, with no implication that one is achieved by execution of the other, as in the following instruction for a jar opener: 
(30) Serrer la poignée de blocage d'une

Tighten the blocking-handle writh one

main en maintenant le bocal de

hand while holding the jar with

l'autre main.(Tefal)

the other hand.

The next example illustrates a further common realization using "pour" which reinforces the observation that generated actions and eviclences appearing in the same sentence are expressed differently:

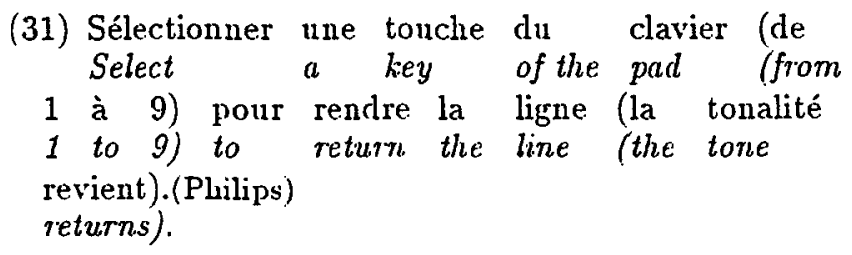

It is worth noting that, althongh "pour" and "afin de" are generally considered interchangeable in this syntactic construction, the latter is, in our corpus, used exclusively to express Generation while "pour" realizes both procedural relations.

Expressing Enablement in French It is in the expression pour infinitive that Generation and Enablement overlap. However, the construction so strongly signals Generation for French readers that they may have difficulty construing an Enablement relation:

(32) Dévisser le flotteur de son bras pour
Unscreu the float from its arm for
le remplacer.(Castorama 50.11)
it to reneu.

(33) Tracer deux parallèles à l'axe Draw two parallel-lines to the axis

vertical pour tapisser lintérieur du vertical for to paper the inside of the

cadre.(Castorama 70.04)

frame.

While the intermediate steps between action and goal are obvious in example 32, it is far from self-evident in example 33 that the action enables the placing of the moulding that will frame the wall-paper when it is eventually hung.

Interestingly, in half of its occurrences in Enallement expressions, "pour" precedes "ponvoir" ("to be able"): making the goal explicitly an enabling state and denying other expectations:

(34) Diluer la peinture pour ponvoir la Dilute the paint for to be able it pulvériser. (Castorama 20.11)

to spray.

The unarceptability of the following example supports this analysis:

(35) ?? Flip the switch to be able to turn on the light.
The most frequent realisation within the sentence is with the conjunction "et" ("and"), which coincides with the English findings:

$$
\begin{aligned}
& \text { (36) Démonter la buse et la nettoyer } \\
& \text { Dis-assemble the nozzle and it clean } \\
& \text { avec un petit } \\
& \text { with a binceau.(Castorama 20.11) } \\
&
\end{aligned}
$$

Temporal markers of sequence account for the remaining $41 \%$ of the examples. By definition, they cannot express Generation. In contrast to the English results, we noted a number of instances of "après" ("after"), as well as "avant" ("before"):
(37) Démonter le réservoir après avoir Dismantle the tank after having dévissé les deux unfastened the two vis de fixation. (Castorama 20.11) fixing screws.

The ordering of the action descriptions in the text is the reverse of that required in the world. The same is often true, of course, of expressions using "avant". However, the latter appear calculated to preempt rather than provoke a rash action on the part of the reader.

\section{The Portuguese Results}

The Portuguese corpus discussed here comes from 8 sets of instruction manuals written in Brazilian Portuguese. The manuals are taken from consumer products; they are aimed at a non-specialist audience and they vary from between 2 to 7 pages in length. As with our analysis of the French data, we set ourselves the task of examining the relationships between the Generation and Enablement relations and syntactic forms in approximately 30 examples of each relation. In what follows, we present the result of our analysis of the 33 Generation and 32 Enallement relations taken. A detailed accounting of the grammatical forms used to express Generation relations is shown in table j. Similar statistics for Enablement relations are shown in table 6 .

The results of these mappings, displayed graphically in figure 6, show a pattern of almost exclusive use of grammatical realizations for the two underlying relations; we will argue that in fact there is no overlap in our data between expressions of the two relations. In general, the pattern of results for Portuguese is rather closer to our findings for French than for English.

Expressing Generation in Portuguese In our Portuguese data, expressions of Generation most often involve the "para" connective, primarily followed by an infinitive (Para + Infinitive) and on rarer occasions by a nominal phrase (Para Noun). Consider, for example, the following instructions from manuals for an electric saw and a mini vacunm cleaner: 


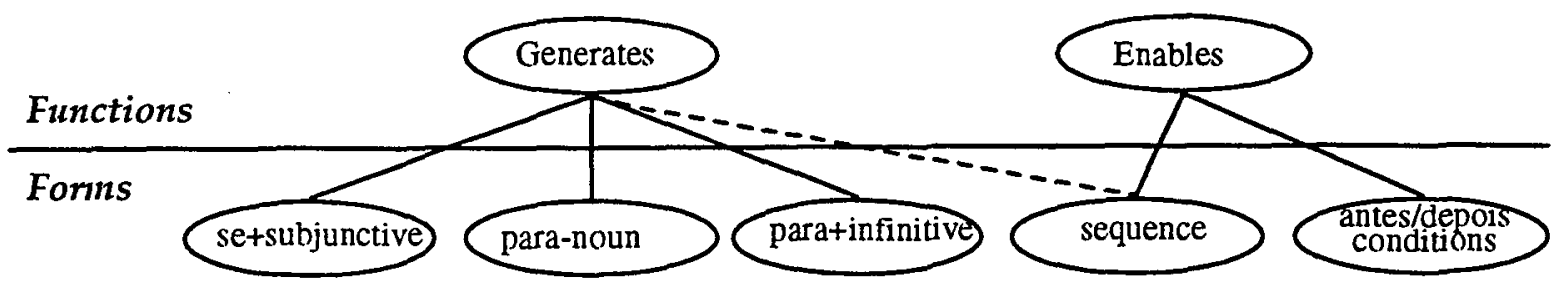

Figure 6: The Portugnese function to form mapping of Generation and Enablement Relations

\begin{tabular}{lcc} 
Grammatical Form & Count & Percentage \\
\hline Para+Infinitive & 23 & $70 \%$ \\
Se+Subjunctive & 3 & $9 \%$ \\
Para+Phrases & 2 & $6 \%$ \\
Seruence & 1 & $3 \%$ \\
2 other forms & 4 & $12 \%$ \\
\hline \multicolumn{1}{c}{ Total: } & 33 &
\end{tabular}

Table j: The frequency of Portuguese grammatical forms for Generation Relations

\begin{tabular}{lcc} 
Grammatical Form & Count & Percentage \\
\hline Secguence & 25 & $78 \%$ \\
Depois Conditions & 4 & $12 \%$ \\
Antes Conditions & 3 & $9 \%$ \\
\hline \multicolumn{1}{c}{ Total: } & 32 &
\end{tabular}

Table 6: The freciuency of Portuguese grammatical forms for Enablement Relations

(38) Para colocar a serra na posição de To put the saw in the position of corte oblícuro, solte a porca borboleta e cut oblique free the screw butterfiy and incline a sapata para o ângulo incline the shoe to the angle desejado.(BlackstDecker) desired.

(39) Para a montagem, encaixe os For the mounting, fit the implementos conforme demonstra a implements consistent with what shows the figura 07 .(Dustbuster)

figure $0 \%$

Of the remaining forms, two are a direct conserpuence of the preference for using para forms, combined with the tendency in the language towards long sentences. A good example of this is shown in the following; taken from a manual for a garden tractor:

$$
\begin{array}{lll}
\text { A CADA } & 100 & \text { HORAS, } \\
\text { Every } & 100 & \text { hours, }
\end{array}
$$

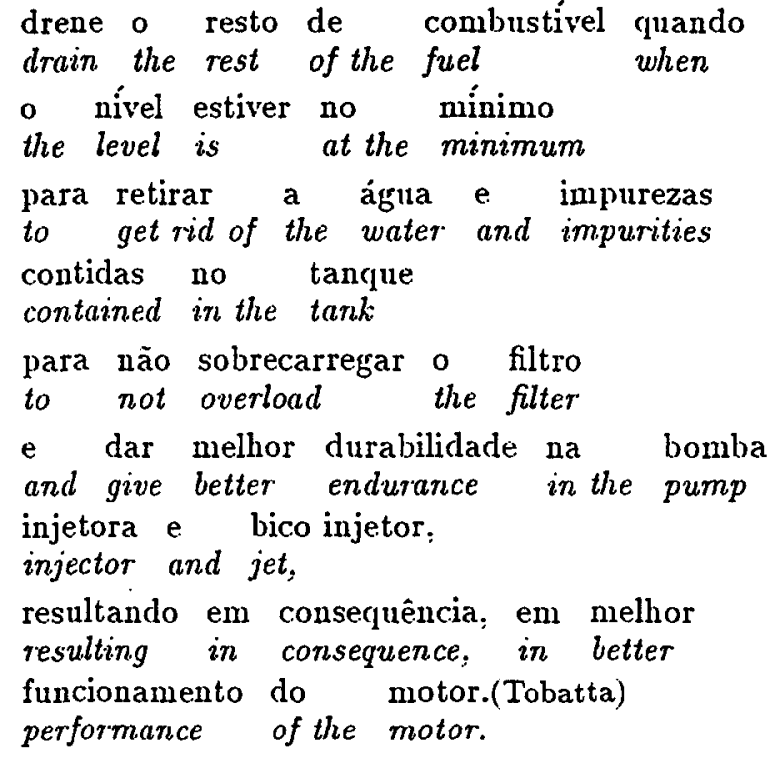

Sentences such as these, with long chains of Generation relations, are not unique in Brazilian Portuguese As noted, the preferred signal of the Generation relation is "para". For stylistic reasons (i.e.. to avoid using the same connective to link the four instances of Generation within this sentence), the anthor has chosen to introduce some elegant variation. The third connective "e" ("and") appears as a Sequence, but what is in fact happening here is that the author has eliderl the "para" from the expression "e para" ("and to"). Sequence is in fact reserved for Enablement, but here the "e" (a typical example of a Sequence marker) is not misleading, since the reader has been primed by the 'rhythm' of the preceding sequence of "para"s to interpret it as yet another one. Sinularly, the choice of the expression resultando em consequência seems to be motivated by the desire to avoid using yet another para. This expression of Generation on its own would be extremely awkward:

(41) ?? Não sobrecarregue o filtro Do not overload the filter.

resultando em consequiiencia en melhor resulting in consequence in better funcionamento do motor. performance of the motor.

\footnotetext{
${ }^{1}$ This example demonstrates the transitivity feature of Generation, discussed by Goldmau (1970).
} 
Expressing Enablement in Portuguese The 8 Portuguese manuals we report on here contained many fewer instances of Enablement than Generation. Interestingly; although para is normally also the default expression of Enablement, we found no instances of it in our data, presumably because this form is such a strong marker of Generation. Instead, we find Enablement to be expressed through signals of the temporal ordering of the actions involved. This we refer to as Sequence: a string of imperatives, either in consecutive sentences, or within a sentence and linked by the conjunction "e" ("and").

(42) Recoloque o filtro de pó e monte Re-put the filter of dust and mount novamente o aparelho.(Dustbuster) once again the appliance.

or Antes/Depois Conditions, seruential steps signaled by the use of "antes de" ("before") or "depois de" ("after") or their equivalents (e.g. "diante" ("before") or "após" ("after")):

(43) Antes de usá-lo leia atentamente as Before using it read carefully the instruções.(Dustbuster) instructions:

(44) Após colocar o plugue na tomada; After to put the plug in the outlet, pressione para baixo a tecla do press dounwwards on the liey of the interruptor.(Café Qnatro coffee macline) interruptor.

As in the French examples, the use of expressions such as antes de tend to arise in cases where the writer appears to be attempting to preempt rather than provoke a rash action, as in the following:

Desligue a serra da tomada, antes de
Unplug the saw from the outlet, before
fazer qualquer ajuste.(Blackd-Decker)
to make uhatever adjustment.

\section{Discussion}

Our study so far provides some important guidelines for representing and expressing Generation and Enablement, which we are soon to begin implementing in our system for generating multilingual drafts of instructions for software use and for carrying out administrative procedures. The Generation and Enablement relations have proved here to be a valuable means for capturing, in a language-independent form, some of the deep semantic relationships underlying procedures. The data analysis we report on has suggested the range of appropriate syntactic expression of Generation and Enablement in English, French and Portuguese, and regions of potential ambiguity. For example, the inclications are that Pour infinitive expressions in French should be avoided where possible (except where followed by "pourvoir"). as should be expressions in English which use the To infinitive despite the fact that they are by far the most frequent form of Generation in our English corpus.

Clearly, the results we present here are only indicative; as we increase the size of our corpus we expect to gain a clearer picture of the relationships between the procedural relations and their linguistic expressions. So far we have not examined the influence of the wider context in which the instances of Generation and Enablement occur in the corpus, and although we are informed on the allowable and preferable mappings from Generation and Enablement to language, we are not yet in a position to identify the influences affecting the selection of the most appropriate expression for a given instance of Generation or Enablement in a particular context. In addition. the rôle of RST in our final architecture is still not clear; we suspect that if a rôle exists, it will be to inform the choice of expression from within the allowable set.

\section{Acknowledgments}

We are grateful to Lucia Rino for her comments on the Portuguese material and to our three annonymous reviewers.

\section{References}

Balkanski, C. T. (1993). Actions, Beliefs and Intentions in Multi-Action Utterances. PhD thesis, Harvard University.

Delin, J., Scott, D., and Hartley, T. (1993). Knowledge, intention, rhetoric: Levels of variation in multilingual instructious. In Proceedings of the Workshop on Inten. tionality and Structure in Discourse Relations, Jume 21, Columbus, $\mathrm{OH}$, pages $i-10$.

Di Eugeuio, B. (1992). Understanding natural langnage instructions: The case of purpose clauses. In Proceedings of the Annual Meeting of Association for Computational Linguistics, Newark, DE, pages $120-127$.

Fikes, R. E. and Nilssou, N. (1971). STRIPS: a new approach to the application of theorem proving to problem solving. Artificial Intelligence, 2:189-208.

Goldman, A. I. (1970). A Theory of Buman Action. Preutice Hall, Englewood Cliffs, NJ.

Mann, W. C. and Thompson, S. A. (1988). Rhetorical structure theory: Toward a functional theory of text organization. Text: An Interdisciplinary Journal for the Study of Text, 8(2).

Pollack, M. E. (1986). Inferring Domain Plans in QuestionAnsuering. PhD thesis, University of Pennsylvania. SRI Technical Report SRIN-403.

Rösner, D. and Stede, M. (1992). Customizing RST for the automatic production of technical mamuals. In Dale, R., Hoyy; E., Röesner, D., and Stock, O., editors, Aspects of Automated Natural Language Generation, Lecture Notes in Artificial Intelligence 58T, pages 199-214. Springer Verlag, Berlin.

Sacerdoti, E. D. (1977). A Structure for Plans and Behavior. Elsevier, New York.

Vauder Lindeu, K. (1993). Speaking of Actions: Choosing Rhetorical Status and Grammatical Form in Instruc. tional Text Generation. PhD thesis, University of Colorado. Available as Techuical Report CU-CS-654-93. 